\title{
Localized Excitatory Synaptic Interactions Mediate the Sustained Depolarization of Electrographic Seizures in Developing Hippocampus
}

\author{
John W. Swann, ${ }^{1,2,3,4}$ Karen L. Smith, ${ }^{1,4}$ and Robert J. Brady ${ }^{3,4}$ \\ ${ }^{1}$ The Cain Foundation Laboratories, Department of Pediatrics, and ${ }^{2}$ Division of Neuroscience, Baylor College of Medicine, \\ Houston, Texas 77030, '3Department of Biomedical Sciences, University at Albany, State University of New York, Albany, \\ New York 12201-0509, and 4Wadsworth Center for Laboratories and Research, New York State Department of Health, \\ Albany, New York 12201-0509
}

Repetitive synchronized neuronal discharging that lasts for seconds and even minutes in in vitro brain slice preparations are important new models in experimental epilepsy. In hippocampal slices from 1-2-week-old rats, individual CA3 pyramidal cells undergo a sustained depolarization during such electrographic seizures, induced by $\mathrm{GABA}_{\mathrm{A}}$ receptor antagonists. In experiments reported here these events were produced in small isolated segments of the CA3 subfield, measuring only $400-500 \mu \mathrm{m}$ along the cell body layer. In such minislices local application of either kynurenic acid or 6-cyano-7-nitroquinoxaline-2-3-dione (CNQX) to the proximal basilar dendrites abolished the synchronized discharges of electrographic seizures. Interictal spikes appeared unaffected by this treatment. Application of these excitatory amino acid receptor antagonists to distal basilar dendrites or apical dendrites was ineffective.

In "larger" minislices, measuring 700-1000 $\mu \mathrm{m}$ along the cell body layer, application of kynurenic acid, CNQX, or TTX to the proximal basilar dendrites did not abolish electrographic seizures but instead selectively suppressed the intracellularly recorded sustained depolarization and the coincident slow negative field potential recorded in proximal basilar dendrites. Results of several experiments suggest that electrographic seizures recorded under these conditions were produced by a remote network of "generator cells." Since the remote neurons were unaffected by local application of the drugs, it seemed likely that they continued to undergo a sustained depolarization. Simultaneous blockade of basilar dendritic synapses in the "generator" population abolished electrographic seizures throughout these larger minislices. These results suggest that the sustained depolarization plays a central role in seizure generation and that it does not have to be generated in every neuron, only in a critical number of "generator cells" for a seizure to occur.

Taken together, results presented here suggest that the sustained depolarization of electrographic seizures is a sep-

\footnotetext{
Received Feb. 4, 1991; revised Apr. 27, 1993; accepted May 6, 1993.

This study was supported by NIH Grants NS18309 and NS23071. We thank Drs. Martha Pierson, David Martin, and David Carpenter for their comments on an earlier draft of the manuscript.

Correspondence should be addressed to John W. Swann, The Cain Foundation Laboratories, Department of Pediatrics, Baylor College of Medicine, One Baylor Plaza, Houston, TX 77030.

Copyright (c) 1993 Society for Neuroscience $0270-6474 / 93 / 134680-10 \$ 05.00 / 0$
}

arate physiological process from the more rapid repetitive depolarizations of the seizure discharges and is required if electrographic seizures are to occur. This slow depolarization appears to be synaptically mediated and generated exclusively in proximal basilar dendrites. Therefore, in addition to the excitatory synaptic potentials involved in paroxysmal depolarization shift generation, a second form of recurrent excitation may exist in immature hippocampus. Not only is this physiological process critical for the genesis of seizures, but it also appears to be highly partitioned within the hippocampal laminae.

IKey words: hippocampus, seizures, excitatory synapses, sustained depolarization, development, epilepsy, dendrites]

Intracellular recordings of electrographic seizures were first reported in animal models of epilepsy over 30 years ago (Kandel and Spencer, 1961a,b; Sawa et al., 1963; Matsumoto and Ajmone-Marsan, 1964; Creutzfeldt et al., 1966; Dichter and Spencer, 1969). These studies showed that a seizure could begin as an intense depolarization, arising abruptly from the resting membrane potential. This initial event was referred to as a paroxysmal depolarization shift (PDS). The earliest recordings also showed that the PDS was a separate event from the remainder of an electrographic seizure since it was observed in isolation between electrographic seizures. In this context the PDS became accepted as the intracellular correlate of the interictal spike of focal epilepsy. When a seizure occurred, the PDS was followed by similar intense depolarizations that were generated in a repetitive and rhythmic manner. Unlike the PDS, the latter discharges did not arise from the resting membrane potential but instead from a sustained membrane depolarization. Recordings suggested that the sustained depolarization might be synaptically mediated (Matsumoto and Ajmone-Marsan, 1964). The significance of the sustained depolarization was debated by early investigators. Some felt that it was essential for seizure generation (Sawa et al., 1968). Others did not (Purpura et al., 1966).

Over the intervening years, little progress has been made in understanding the role the sustained depolarization plays in seizure generation. This stems in large part from a lack of simple but relevant experimental models. However, studies in in vitro slice preparations have greatly expanded an understanding of the cellular mechanisms responsible for generation of the PDS. Studies have shown that recurrent excitatory synaptic trans- 
mission contributes importantly to its generation (Johnston and Brown, 1981; Gutnick et al., 1982; Traub and Wong, 1982; Wong and Traub, 1983). In addition, in the hippocampal CA3 subfield, laminar field potential and current source-density analyses suggest that the PDS is generated at discrete sites on apical and basilar dendrites of hippocampal pyramidal cells (Swann et al., 1986a,b). Recent anatomical studies have shown that it is at these sites that recurrent excitatory synaptic contacts are made between hippocampal pyramidal cells (Deitch et al., 1990, 1991; Ishizuka et al., 1990).

Early, in vivo recordings suggested that the sustained events of electrographic seizures were also generated at discrete sites. For example, during hippocampal seizures, Gloor et al. (1964) recorded a slow negative field potential that was localized to the basilar dendritic layer. Recently, a number of in vitro models have been described in which electrographic seizures have been recorded (Swann and Brady, 1984; Taylor and Dudek, 1984; Anderson et al., 1986; Konnerth et al., 1986; Hablitz, 1987; Traynelis and Dingledine, 1988). Recordings in slices of developing area CA3 confirmed the findings of Gloor et al. (1964) in that a slow negative field potential was recorded in the basilar dendritic layer during electrographic seizures (Swann et al., 1986a,b). Coincident with this field potential, the sustained depolarization was observed intraccllularly. Furthermore, results from laminar field potential analyses in these studies suggested that the sustained potential was generated on proximal basilar dendrites while the PDS was produced simultaneously on central portions of both apical and basilar dendrites.

Based on these observations, it seemed plausible that the sustained depolarization and PDS are generated separately in the same cell by activation of synapses or voltage-dependent currents located at different sites on hippocampal dendrites. This is the focus of studies reported here. In general, anatomic and physiologic studies support the view that the microcircuitry of the CNS is highly organized. In recent years detailed descriptions of the segregation of projections of intrinsic neurons in neocortex and hippocampus have been provided (Andersen, 1975; Amaral, 1978; Gilbert, 1983; Gilbert and Wiesel, 1983; Valverde, 1986; Amaral and Witter, 1989). Signaling within networks is also orchestrated by the differential distribution of ion conductances in dendritic membranes (Llinas, 1988). Electrophysiological studies of voltage-dependent $\mathrm{Ca}^{2+}$ conductances and imaging of neurons with $\mathrm{Ca}^{2+}$-sensitive dyes perhaps provide the clearest examples of nonuniformity in the distribution of channels over neuronal membranes (Ross and Werman, 1987; Tank et al., 1988; Jaffe et al., 1992).

Accordingly, the experiments reported here were undertaken to examine the origins of the sustained depolarization and to ask whether the potential is produced locally on hippocampal dendrites. Our results suggest the sustained depolarization is mediated by activation of recurrent excitatory synapses located on the proximal basilar dendrites of CA3 pyramidal cells. It is inferred that the sustained depolarization is produced by a physiologic process separate from that generating the PDS. Furthermore, the occurrence of the sustained depolarization appears to be required for transition from interictal events into full-blown electrographic seizures.

\section{Materials and Methods}

Hippocampal slices were taken from rats $10-15 \mathrm{~d}$ of age by methods previously described (Swann and Brady, 1984). Transverse slices were cut $500 \mu \mathrm{m}$ thick. Using a stereomicroscope, segments (hereafter referred to as minislices) were dissected from the CA3 subfield of each slice. A photograph of one such minislice is shown in Figure 1. Two cuts were made with a shard of razor blade orthogonal to the cell body layer (see dashed line in inset, panel 2). The minislices werc transferred to an experimental chamber and perfused with artificial cerebrospinal fluid. Its composition was (mM) $122.75 \mathrm{NaCl}, 5.0 \mathrm{KCl}, 2.0 \mathrm{CaCl}_{2}, 2.0 \mathrm{MgSO}_{4}$, $1.25 \mathrm{NaH}_{2} \mathrm{PO}_{4}, 26.0 \mathrm{NaHCO}_{3}$, and 10 glucose. After equilibration for approximately $1 \mathrm{hr}$, epileptiform discharging was produced in all experiments by bath-applied penicillin $(1.7 \mathrm{~mm})$. Experiments were performed at $32-33^{\circ} \mathrm{C}$.

Intracellular recordings were made from the pyramidal cell body layer with glass microelectrodes filled with $4 \mathrm{M} \mathrm{K}$-acetate and having DC resistance of 100-200 M . Extracellular field recordings were obtained with electrodes filled with $2 \mathrm{M} \mathrm{NaCl}$ that were $10-20 \mathrm{M} \Omega$ in resistance. Events were electrically evoked by a monopolar stimulating electrode in the distal portion of the apical dendritic layer.

Kynurenic acid (KYN) (0.5-1.0 mM), 6-cyano-7-nitroquinoxaline-23-dione (CNQX) $(50-100 \mu \mathrm{M})$, or tctrodotoxin (TTX) $(100 \mu \mathrm{M})$ was applied via a pressure micropipette as microdroplets $(1-10 \mathrm{ml})$ to the surface of slices at selected locations. Due to dilution of drugs when applied as microdroplets, a 5-10-fold increase in the concentration over that used for bath application is usually required to achieve similar effects. For instance, in a perfusion solution, KYN and CNQX suppress afterdischarging at concentrations of $100 \mu \mathrm{M}$ and $5 \mu \mathrm{M}$, respectively.

In some experiments the use of CNQX was advantageous since its effects did not reverse as readily as those of KYN. Thus, a steady state effect could be achieved and more easily quantified. However, when demonstration of the reversal of drug effects with washout was desirable, KYN was employed.

All recordings were DC coupled and referred to a remote $\mathrm{Ag} / \mathrm{AgCl}$ bath ground. Conventional techniques were employed to amplify and display signals. Data were stored on FM magnetic tape (DC to $5 \mathrm{kHz}$ ). Selected portions of experiments were digitized and analyzed with PDP 11/23-based or BRAINWAVE SYSTEM-based software. Recordings were drawn with either a Hewlett-Packard $x-y$ plotter or laser jet printer. In those instances when prolonged recording periods are illustrated, these were played back onto a Gould rectilinear pen recorder.

\section{Results}

Examples of penicillin-induced epileptiform discharges are shown in Figure 1. These recordings were taken from a minislice of the CA3 subfield (see inset, panel 2). When minislices were longer than $500 \mu \mathrm{m}$ (measured along the cell body layer), nearly all (95 out of 101) generated discharges structurally identical to those obtained from intact slices. Typically, the recorded events alternated between brief and prolonged discharges (panel 1). Each discharge began as a PDS (arrow, panels 3 and 4) and a coincident extracellularly recorded interictal spike. The PDS was followed by an afterdischarge consisting intracellularly of rhythmic repetitive depolarizations (denoted by dots below traces $A$ in panels 3 and 4). Simultaneously, the synchronous discharging of the population was recorded extracellularly (traces B). Following each PDS individual neurons underwent an additional slow depolarization. The repetitive depolarizations of electrographic seizures rode the envelope of this potential, which became sustained during the seizure-like events as seen in panels 1 and 4. Since this sustained depolarization was such a prominent feature of the seizure-like discharges and because it has been previously implicated as an important contributor to epileptogenesis, studies were undertaken to explore how this prolonged depolarization is produced

Coincident with the sustained depolarization a slow negative field potential (Fig. 1, trace B) was recorded in the proximal portion of the basilar dendritic layer. Accordingly, in experiments reported here the intracellularly recorded sustained depolarization and the basilar dendritic slow potential were hypothesized to be measures of the same physiological events and 

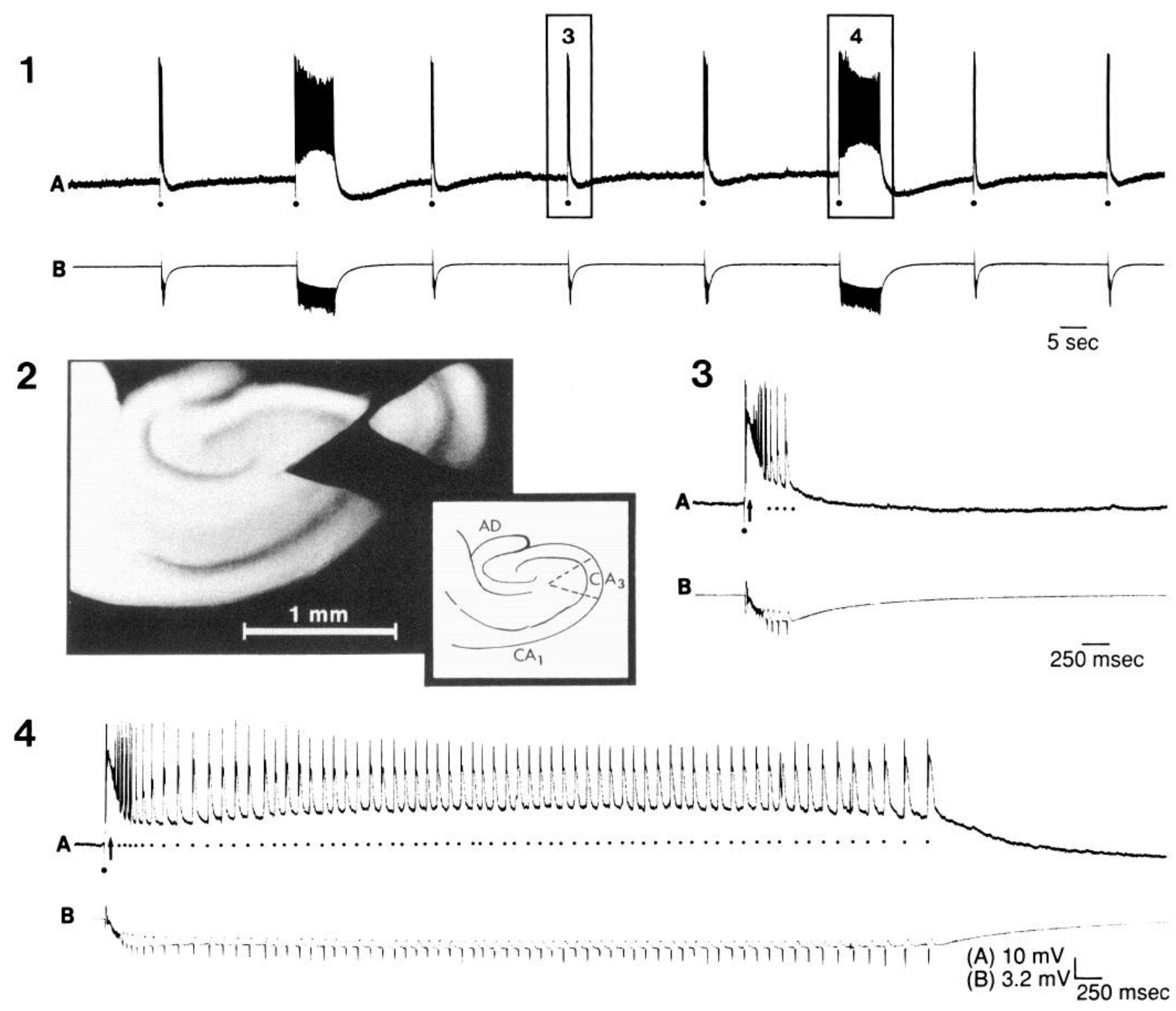

Figure 1. Epileptiform activity recorded in minislices of the CA3 subfield of immature hippocampus. The minislices were made by two cuts orthogonal to the CA3 cell body layer (dashed lines, panel 2 inset). In panel 1 , simultaneous intracellular (trace A) and extracellular (trace B) field recordings are shown. Intracellular recordings were from the cell body layer. Extracellular recordings were from the proximal portion of the basilar dendritic layer. All events were triggered by a monopolar stimulating electrode placed in the stratum radiatum. Dots below trace $A$ indicate when a stimulus was applied. The events labeled 3 and 4 are shown below at an expanded time base. In panels 3 and 4 the arrow indicates the PDS in trace $A$. The initial dots indicate stimulus application, while the subsequent dots denote each synchronized discharge of the afterdischarge.

produced by activation of recurrent excitatory synapses on proximal basilar dendrites. To support this hypothesis, excitatory amino acid receptor antagonists should abolish the sustained depolarization if applied locally to basilar dendrites. Moreover, if this sustained depolarization were important to the generation of electrographic seizures, such treatments should abolish these events.

Results from one such experiment are shown in Figure 2. Figure $2 C$ shows the experimental arrangement. Three simultaneous recordings were made. Intracellular events were recorded with microelectrode $\mathrm{A}$, while electrodes $\mathrm{B}$ and $\mathrm{C}$ recorded extracellular fields in the basilar and apical dendritic layer, respectively. Events were electrically evoked using a repetitive $(0.1-0.2 \mathrm{~Hz})$ stimulation protocol previously described (Smith and Swann, 1987). This protocol allows brief $(<1 \mathrm{sec})$ synchronized afterdischarges of relatively constant duration to be repeatedly evoked for several hours. By avoiding discharges of variable duration (Fig. 1), the protocol facilitates the quantitation of pharmacologic effects shown in Figure 3.

Recordings in Figure $2 A$ show that afterdischarge generation ceased when a droplet of KYN (1 mM) was applied to the proximal basilar dendrites $(A-2)$. Nonetheless, the PDS persisted (trace $\mathrm{A}$ ) and the coincident interictal spike was unchanged (traces B and C). In contrast, the identical application of KYN to the apical dendrites (Fig. 2A-3) did not block afterdischarges. Field recordings from the apical dendritic layer (trace $\mathrm{C}$ in Fig. $2 A-3$ ) show that the polarity of the signals was reversed by the drug. When the drug was locally applied to the basilar dendritic layer (Fig. 2A-2) the interictal spike recorded in the apical dendritic layer (trace $\mathrm{C}$ ) was unaltered. This shows that drug ap- 

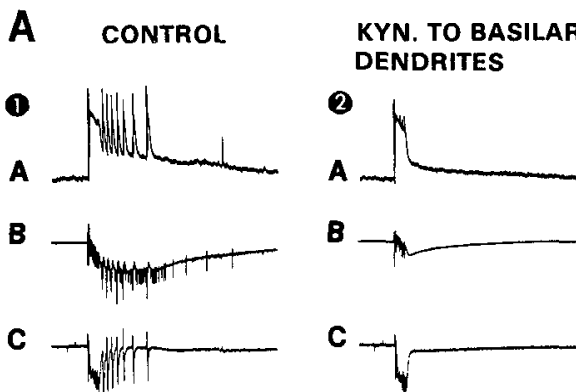

2

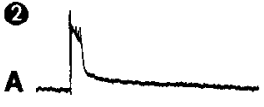

B
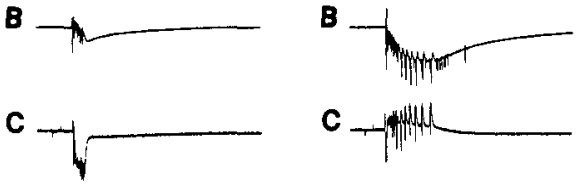

\section{DENDRITES}

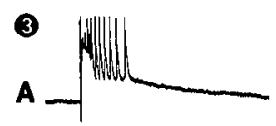

$\mathbf{B}$
WASH

(A) $20 \mathrm{mV}$
(B) $4 \mathrm{mV}$
(C) $1.45 \mathrm{mV}$

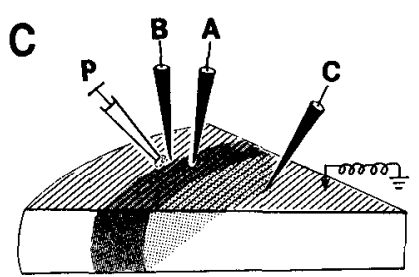

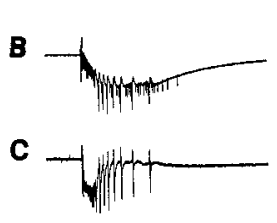

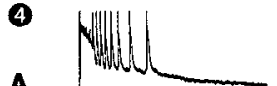

A
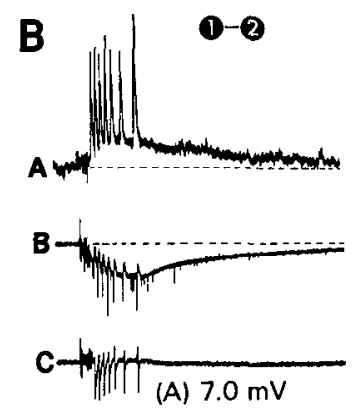

(B) $2.0 \mathrm{mV}$

(C) $1.1 \mathrm{mV} \frac{}{600} \mathrm{msec}$

Figure 2. Application of KYN to the proximal basilar dendrites selectively suppressed synchronized afterdischarges. Panel $C$ shows the recording arrangement. An intracellular recording electrode (labeled $A$ ) was located in the cell body layer. Extracellular field recordings were made simultaneously in the proximal portion of the basilar dendrites (electrode $B$ ) and center of the apical dendritic layer (electrode $C$ ). Recordings in panels $A$ and $B$ are labeled to correspond to the electrodes from which they were obtained. Events were evoked electrically by a stimulating electrode in the distal portion of the apical dendritic layer. KYN was locally applied to the surface of the slice via a pressure $(P)$ micropipette. In panel $A$ the effects of applying KYN (1 mM) to the basilar and apical dendrites are compared. After application to the basilar dendrites the drug was allowed to wash out and afterdischarges resume before the pressure pipette was moved to the apical dendritic layer. Traces in $B$ were produced by digitally subtracting events in $A-2$ from those in $A-1$.

plication was quite local and the ability of KYN to block afterdischarges is likely due to its actions in the basilar dendrites. These results were reproduced in each of eight separate experiments.
In addition to KYN, we also studied the effects of CNQX on afterdischarge generation. CNQX is a more specific excitatory amino acid antagonist, structurally unrelated to $\mathrm{KYN}$, which preferentially acts at the AMPA receptor (Honore et al., 1988).
A

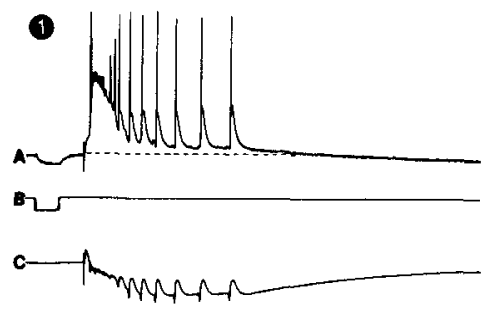

(อ)

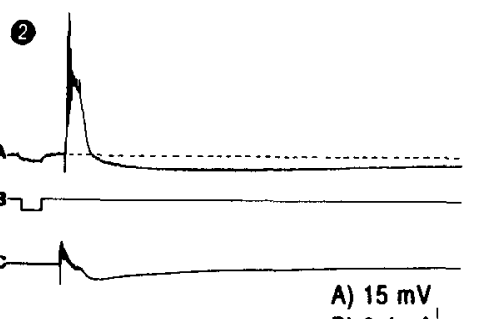

B) $0.4 \mathrm{nAL}$

C) $5 \mathrm{mV} 200 \mathrm{msec}$
B

No. OF DISCHARGES DISCHARGE
DURATION DURATION MEMBRANE
POTENTIAL

MEMBRANE RESISTANCE

INTERCELLULAR DEPOLARIZATION DURATION DURATION SLOW POTENTIAL

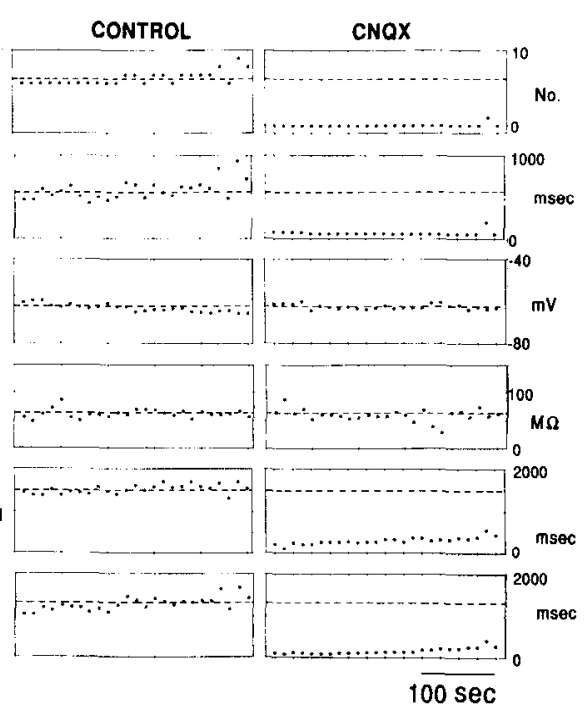

Figure 3. Local application of CNQX $(50 \mu \mathrm{M})$ to proximal basilar dendrites suppressed synchronized afterdischarges and concomitantly decreased the duration of the intracellular depolarization and the basilar dendritic slow potential. Panel $A$ shows representative intracellular $($ trace $A$ ) and extracellular (trace $B$ ) field potential recordings taken before $(A-1)$ and after $(A-2)$ CNQX application. Trace $B$ is a monitor of intracellular current injection. In panel $B$ the effects of CNQX application to the basilar dendrites were quantified. In this panel the number of discharges in each synchronized afterdischarge and duration of the epileptiform discharge were plotted before and during CNQX application. The membrane potential and resistance of the cell were simultaneously measured. Membrane resistance was monitored by the amplitude of membrane hyperpolarization produced by a $100 \mathrm{msec}$ square wave pulse of current injected via the recording electrode under bridge balance. The duration of membrane depolarization was the time measured from the onset of the stimulus to when the cell returned to resting potential. The duration of the slow negative field potential was measured at half-maximal amplitude in basilar dendritic recordings. 

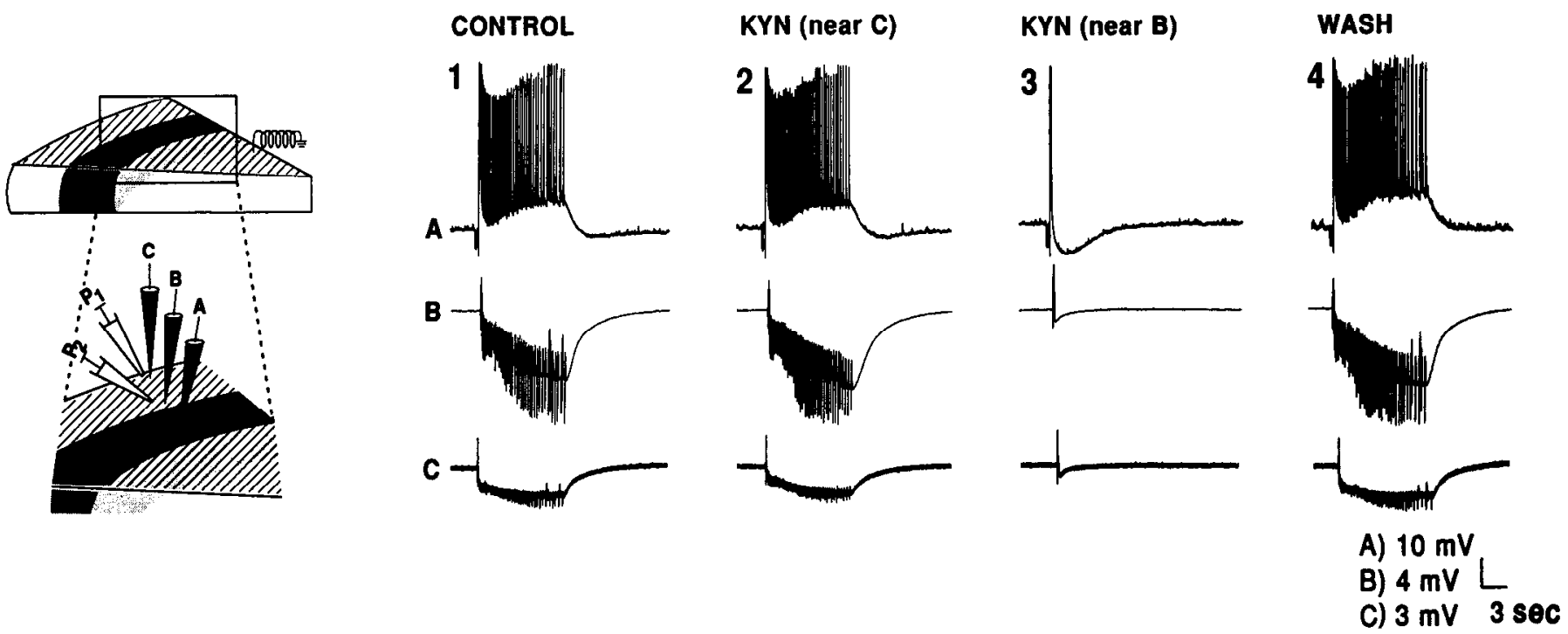

Figure 4. Application of KYN (1 mM) to distal basilar dendrites did not suppress synchronized afterdischarging. Panel on the left illustrates the recording arrangement. Intracellular electrodes were placed in the cell body layer. Extracellular field potentials were recorded simultaneously from proximal (electrode B) and distal (electrode $C$ ) aspects of the basilar dendritic layer. Events were electrically evoked. KYN was locally applied from two independent pressure micropipettes: first near electrode $\mathrm{C}$ ( panel 2) and then after a 30 min wash near electrode B (panel 3).

CNQX was found to be an order of magnitude more potent than KYN but its effects on epileptiform discharging were very similar. Figure 3 shows results from an experiment in which CNQX $(50 \mu \mathrm{M})$ was applied locally to the proximal basilar dendrites. Before CNQX the average number of synchronized discharges in an afterdischarge was approximately 7 and the average discharge duration was $631 \mathrm{msec}$. After CNQX (Fig. 3A2) application, afterdischarges were abolished and the discharge duration was reduced to $84 \mathrm{msec}$. This was a measure of the interictal spike that was not blocked by CNQX (Fig. 3A-2). Like $\mathrm{KYN}$, CNQX had no effect on resting membrane potential or resistance. Nonetheless, the time the cell remained depolarized (duration of intracellular depolarization) following each stimulus was greatly reduced, as was the duration of the coincident slow field potential. In six experiments, in which the duration of the depolarization was measured, it decreased from $1.23 \pm$ $0.39( \pm \mathrm{SD}) \mathrm{sec}$ to $0.42 \pm 0.29 \mathrm{sec}$ after CNQX application. This was a $66 \%$ reduction in duration $(P<0.001$, paired $t$ test). The slow potential was likewise decreased by $66 \%$, from 1.19 $\pm 0.16 \mathrm{sec}$ to $0.40 \pm 0.19 \mathrm{sec}(P<0.001)$.

When signals obtained during CNQX or KYN application were digitally subtracted from signals recorded during the control period, the time courses of the eliminated intracellular depolarization and basilar dendritic slow field were remarkably similar. For example, Figure $2 B$ shows signals obtained by subtracting events recorded after KYN treatment from those recorded during the control period.

In another set of experiments KYN was locally applied to different sites within the basilar dendritic layer. In these experiments prolonged electrographic seizures were recorded. As discussed above, the slow negative field potential that correlates in time with the sustained depolarization was most prominent in proximal basilar dendritic layer recordings. Traces in Figure 4 , panel 1 , illustrate this point. Coincident with the intracellular events (A), extracellular field potentials were recorded in proximal (B) and distal (C) aspects of the basilar dendrites. A slow negative field potential was recorded at both extracellular sites; however, the slow event recorded proximally was three to four times larger than that seen more distally as seen in panel 1 . Application of KYN (1 mM) near the distal recording site (panel 2) had no effect on the electrographic seizures. However, at the proximal site (panel 3) an identical drug application blocked these events. Consistent with results in Figures 2 and 3, the interictal discharge was resistant to this treatment. Afterdischarging recovered when KYN was washed from the slice. Similar results were obtained in six separate experiments.

Taken together, the effects of both KYN and CNQX, illustrated in Figures 2, 3, and 4, suggest that an excitatory amino acid-mediated synaptic event occurring in the proximal basilar dendritic layer plays a key role in synchronized afterdischarge generation. Results of the analysis of the slow events in Figures 2 and 3 are fully consistent with the view that a prolonged excitatory amino acid-mediated basilar dendritic current generates the sustained depolarization.

Further study demonstrated that the sustained depolarization is a distinct physiologic event. In these experiments larger minislices (measuring 700-1000 $\mu \mathrm{m}$ along the cell body layer) were used. Thus, the number of neurons participating in the seizure discharges increased. The experimental arrangement is shown in Figure $5 A$. Recordings were made intracellularly (electrode A) and extracellularly with two electrodes (B and C). Both of the field electrodes were placed in the proximal portion of the basilar dendritic layer. Electrodes A and B were within $100 \mu \mathrm{m}$ of each other. Prolonged seizure discharges were examined. Recordings of one such discharge, taken during the control period, are shown in Figure $5 B$. This same discharge is also shown compressed in time and at a higher gain in Figure $5 \mathrm{C}-1$.

In these larger minislices, afterdischarges were not abolished when KYN or CNQX was applied at a single site in the basilar dendritic layer. This would appear to contradict the results of Figures 2, 3, and 4. However, when the drug (KYN, $1 \mathrm{~mm})$ was applied near electrode $\mathrm{B}$ the extracellular slow field recorded at that site was suppressed (trace B, Fig. 5C-2). Most importantly, at the same time the intracellular record (trace A, Fig. 5C-2) 
A



C


B A-
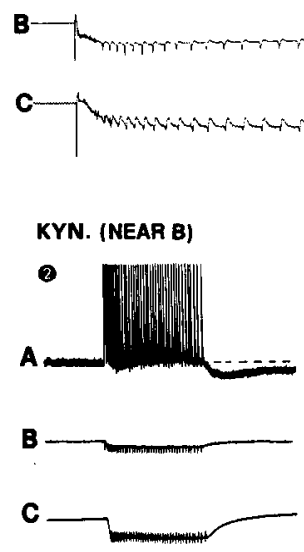

KYN. (NEAR B \&C)

3

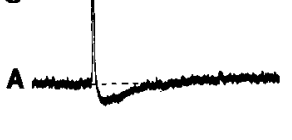

$\mathbf{B} \longrightarrow$

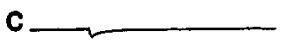

$d\rfloor$

$30 \mathrm{mV}$

(B \& C) $8 \mathrm{mv} \underset{\mathrm{msec}}{200}$

WASH

4
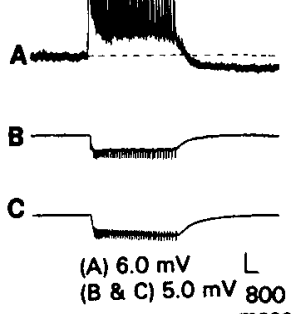

Figure 5. Effects of local application of KYN (1 mM) to the basilar dendritic layer of a "larger" minislice. Panel A shows the experimental arrangement. Recordings were made intracellularly in the cell body layer (electrode $A$ ) and extracellularly from two sites in the basilar dendritic layer (electrodes $B, C$ ). Electrode B was within $100 \mu \mathrm{m}$ of electrode A. Events were electrically evoked. KYN was applied locally with a pressure micropipette $(P)$, first near electrode $\mathrm{B}(C-2)$ and then additionally near electrode $\mathrm{C}(C-3)$. Control recordings in $C-1$ are shown at a faster time base in panel $B$. Spikes in panel $C$ are truncated due to the higher gain used in these traces. shows that the sustained depolarization was eliminated. The afterdischarge now arose either from resting or a slightly hyperpolarized membrane potential. The recordings in Figure $5 C$ 2 suggest ( 1 ) that the sustained depolarization is a separate physiologic process from the repetitive discharges of electrographic scizures, (2) that it is generated in the basilar dendrites, and (3) that it is synaptically mediated.

A critical question is whether the sustained depolarization is required for the genesis of seizures. In Figure $5 C-2$, when the sustained depolarization was abolished, the slow field potential recorded by the electrode remote from the site of drug application was unaltered (trace $C$ ). From this we suspected that the network of neurons at the remote site continued to undergo a sustained depolarization and that the resultant afterdischarges in this remote population were responsible for the generation of synchronized discharges at the site of drug application. According to this scheme the KYN-treated neurons continue to be "driven" by the synchronized discharges produced in the remote network of generator cells. That is, each of the rhythmic depolarizations of an afterdischarge in the generator network produces its counterpart in the follower population.

To test the proposed scheme, a second droplet of KYN was applied near electrode $\mathrm{C}$. This double application resulted in an abrupt cessation of all afterdischarging (Fig. 5C-3). After $15 \mathrm{~min}$ of wash the effects of KYN reversed (Fig. 5C-4). Similar results have been obtained in each of nine experiments. These results suggest that the sustained depolarization does not have to take place in every cell for a seizure to occur but it must be produced in a critical number of generator cells. In this sense it would be required for seizure generation.

Results from two other experiments using "larger" minislices further support the contention that the sustained depolarization is a separate physiologic process. These results are also fully consistent with the proposed roles for generator and follower neuronal populations in the production of electrographic seizures like that shown in Figure $5 C$-2, trace A. The first experiment was similar to that described in Figure 5. However, instead of KYN, TTX was locally applied to the basilar dendrites. The rationale was that if the sustained depolarization is medi- ated by synapses in the basilar dendrites then it should be abolished by TTX. TTX would eliminate action potentials generated presynaptically and thus block transmitter release (Katz and Miledi, 1967). The experimental arrangement was similar to that used in Figure 5. As can be seen in Figure 6A-2, local application of TTX $(100 \mu \mathrm{M})$ selectively eliminated the sustained depolarization. Application was so discrete that action potentials were not abolished. Near electrode $B_{1}$ the slow field potential was eliminated but the remote population appeared to be unaffected (trace C). When additional TTX was applied to this site or another droplet was applied more distally in the basilar dendrites, the repetitive depolarizations of the afterdischarge were reduced in amplitude (Fig. 6A-3). Figure $6 B-3$ shows a selected portion of this discharge at a faster time base. Since this additional effect of TTX was likely due to blockade of basilar dendritic processes that participate in the repeated depolarization of the seizures, the remaining intracellularly recorded events were thought to be generated exclusively in the apical dendrites. Recordings in Figure $6 \mathrm{~A}-4$ are consistent with this notion. Here electrode $B$ was moved from the recording site $\left(B_{1}\right)$ in stratum oriens to stratum radiatum $\left(B_{2}\right)$. Large negative transients, very rcminiscent of field EPSPs, were recorded coincident with each intracellular depolarization during the afterdischarge (see panel $B-4$ for recordings at an expanded time hase).

Under these experimental circumstances it seemed likely that the relationship between the proposed generator and follower neuronal populations invoked to explain results in Figure 5 could be most clearly explored. For instance, if a sustained depolarization in generator neurons near electrode $C$ results in synchronized discharges each of which produced a depolarization in follower neurons near electrode $A$, then each population spike recorded at $\mathrm{C}$ should precede the intracellular depolarization recorded by electrode $A$. Indeed, this was the case. On average, population spikes preceded the intracellular depolarization by $6.32 \pm 2.26 \mathrm{msec}$. Representative traces are shown in Figure $5 C$.

If these depolarizing potentials were in large measure EPSPs produced by the discharging of the remote "generator" population, then they should be suppressed by excitatory amino acid 
A

Figure 6. Effects of local application of TTX $(100 \mu \mathrm{M})$ to the basilar dendritic layer of a "larger" minislice. Schematic drawings at the top of $A-1-A-4$ show experimental arrangements. Initially, recordings were made intracellularly in the cell body layer (electrode $A$ ) and extracellularly from two sites in the basilar dendritic layer (electrodes $\left.B_{1}, C\right)$. In $A-2$ a microdroplet of TTX was applied near electrode $\mathrm{B}_{1}$ via micropipette $P$. In $A-3$ an additional droplet of TTX was applied at this site. Recordings in $A-4$ were taken immediately after those in $A-3$ but electrode B was moved to the apical dendritic layer at recording site $B_{2}$. Recordings in panel $B$ show selected synchronized discharges taken from the electrographic seizures shown in panel $A$. Here they are expanded in time so the detailed structure of the events can be seen more clearly. Recordings in panel $C$ show the timing between population spikes recorded by electrode $\mathrm{C}$ and intracellular depolarizations recorded by electrode $\mathrm{A}$.
CONTROL

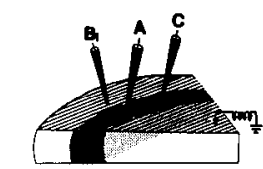

1
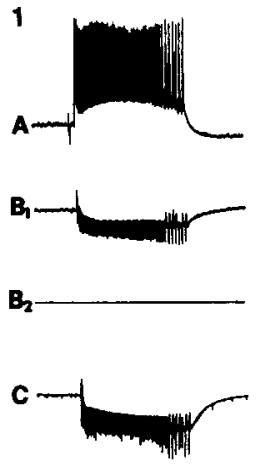

TTX AT B

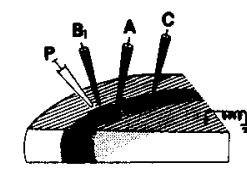

2
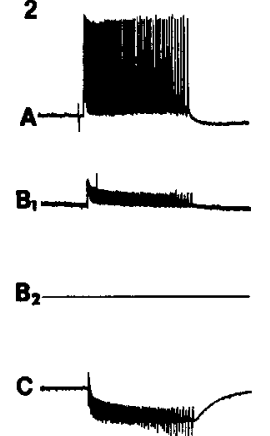

A) $20 \mathrm{mV}$

B) $5 \mathrm{mV}$

C) $5 \mathrm{mV} 4 \mathrm{sec}$

3

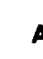

ADDITIONAL TTX AT $B_{1}$


3

4

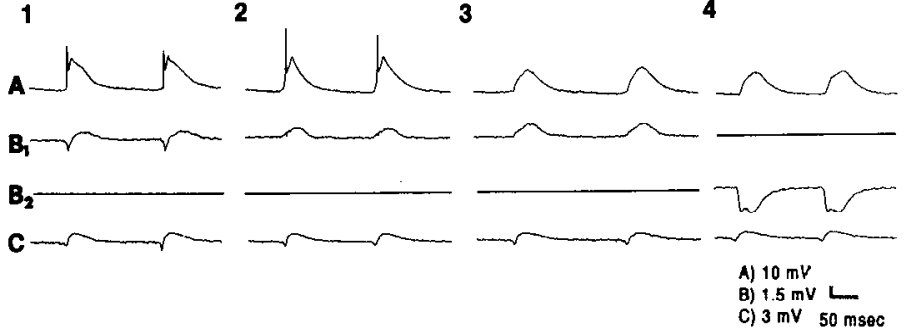

MOVE B

ELECTRODE
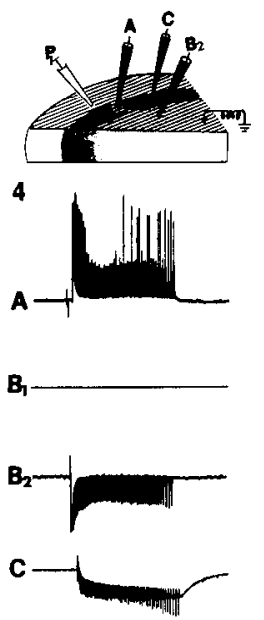

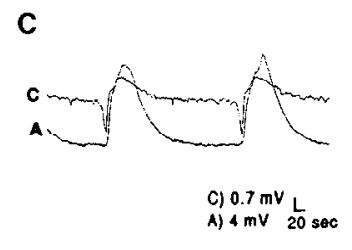

antagonists. To test this hypothesis we applied CNQX to the apical dendrites of the follower population after TTX blockade of events in the basilar dendrites. Results are shown in Figure 7. The experimental arrangement is similar to that in Figures 5 and 6 . In these studies a sixth independently manipulated micropipette was added in order to apply CNQX $(50 \mu \mathrm{M})$ locally. As before, intracellular (A) and extracellular (B and $\mathrm{C}$ ) field recordings were obtained. As shown in Figure 6, TTX application to the basilar dendritic layer abolished the sustained depolarization and diminished the amplitude of the repetitive depolarizing potentials of an afterdischarge (Fig. 7-2, trace A). Electrode B was then moved to the apical dendritic layer, and as shown in Figure 6 large negative transients (Fig. 7-3, trace $B_{2}$ ) coincident with each intracellular depolarization were revealed. In panel 4 application of CNQX near recording site $B_{2}$ climinatcd the negative potentials and the repetitive depolarizations recorded intracellularly. Discharging of the remote population was unaffected (traces $C$ ).

Results in Figures 6 and 7 are fully consistent with the scheme of electrographic seizure generation proposed above. First, in the absence of a sustained depolarization neurons may still undergo an electrographic seizure but these events are produced by the discharging of remote generator cells. Since these data are consistent with the interpretation of results in Figure $5 C-2$, they support the previous conclusion that the sustained depolarization must be produced in a critical number of generator cells if an electrographic seizure is to occur. Furthermore, since application of TTX to the basilar dendrites can selectively eliminate the sustained depolarization (Fig. 6A-2). This supports the

contention that the sustained depolarization is a separate physiological process.

\section{Discussion}

Our studies of the sustained depolarization were initially based on the observation that, coincident with the intracellular depolarization, a slow negative field potential (Fig. 1, traces B) is recorded in the proximal portion of the basilar dendritic layer (Swann et al., 1986a,b). Generally, whenever an excitatory current occurs it is thought to create a negativity in the extracellular space as it produces a depolarization intracellularly. Thus, it seemed plausible that the basilar dendritic slow potential and intracellular sustained depolarization might be produced by the same excitatory process. Previous studies in our laboratory have shown that the synchronized afterdischarge of an electrographic seizure is eliminated by bath application of excitatory amino acid antagonists (Brady and Swann, 1986, 1988). Although at higher concentrations of these drugs the PDS is blocked, it is comparatively resistant to the actions of such agents. These observations led us to suspect that excitatory amino acid antagonists act by blocking a form of synaptic transmission in the proximal portion of the basilar dendrites, and that these EPSPs are in some way responsible for the genesis of the sustained depolarization. If this were true, it follows that the sustained depolarization is required for the generation of electrographic seizures. Results from the experiments reported here are consistent with these ideas.

Results also suggest that two forms of local recurrent excitation may exist in the developing CA3 hippocampal subfield, 


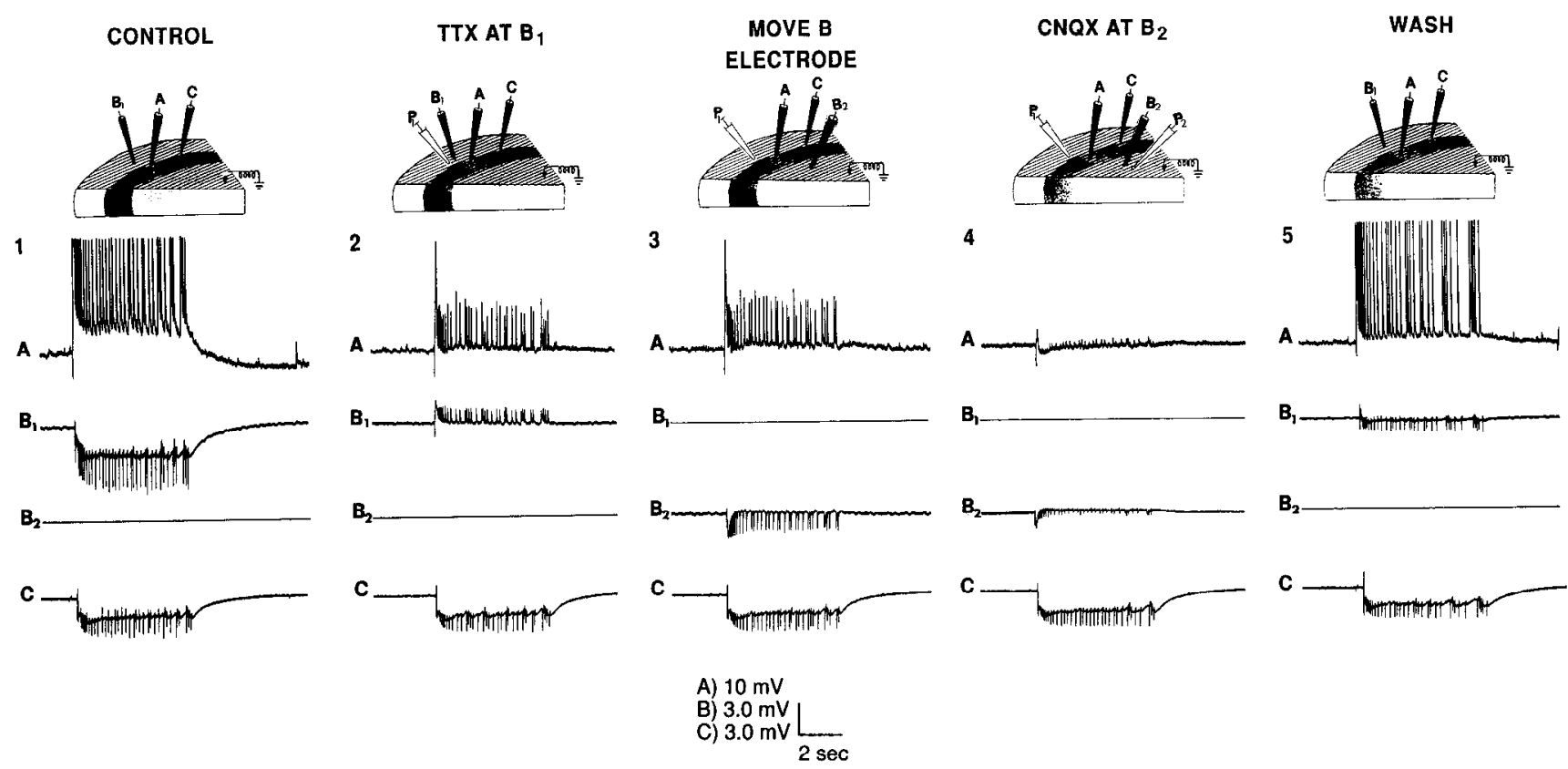

Figure 7. Effects of CNQX application to the apical dendritic layer following blockade of basilar dendritic processes with TTX. The experimental arrangement in each panel is depicted by schematic drawings. Initially, recordings were made intracellularly from the cell body layer and extracellularly from two sites in the proximal portion of the basilar dendritic layer (electrodes $B_{l}, C$ ). In panel 2 TTX (100 $\left.\mu \mathrm{M}\right)$ was applied via pressure micropipette $P_{1}$ to the basilar dendritic layer near electrode B. In panel 3 electrode B was moved from site $B_{1}$ to site $B_{2}$. In panel $4 \mathrm{CNQX}$ (50 $\mu \mathrm{M}$ ) was applied via $P_{2}$ near electrode site $\mathrm{B}_{2}$. Recordings in panel 5 were taken after $1 \mathrm{hr}$ of wash.

each playing different but important roles in epileptogenesis. First, recurrent EPSPs mediate synchronized discharges of pyramidal cells. Not only is the PDS the product of such interactions, but as suggested previously the synchronized afterdischarges are likely mediated by activation of this same group of recurrent excitatory synapses (Miles et al., 1984; Knowles et al., 1987). Second, there appears to be another form of recurrent excitation that underlies the sustained depolarization of electrographic seizures. The sustained depolarization appears to be generated locally in the basilar dendrites.

Numcrous hypotheses might be presented concerning the origin of the synaptic events underlying the sustained depolarization. First, there may be a subpopulation of neurons in the CA3 hippocampal subfield that use an excitatory amino acid as a neurotransmitter and restrict their terminal field to the basilar dendritic layer. Firing of these neurons would generate the sustained depolarization. Second, the sustained depolarization could be generated by discharging of CA3 hippocampal pyramidal cells themselves. In this instance, the sustained depolarization would be the product of a specialized postsynaptic receptor or associated channels that is restricted to the proximal portion of the basilar dendritic tree. Action potentials in pyramidal cell axon terminal fields in this region would in some way lead to prolonged membrane depolarizations. At other sites on dendrites EPSPs produced by other axon collaterals from the same pyramidal cell would be less prolonged, since the postsynaptic conductance mechanism located there would generate only brief depolarizations.

Identification of the physiological process that underlies the prolonged inward current in the proximal basilar dendrites is an obvious avenue for future study. One mechanism that might be suggested is a persistent intrinsic conductance that results in a plateau potential. If the sustained depolarization were pro- duced by such a voltage-dependent intrinsic current, then when a pyramidal cell depolarizes, such a current should be activated. However, in Figures $5 C-2$ and $6, A-2$ and $B-2$, neurons underwent repeated depolarizations during the afterdischarges yet the sustained depolarization was absent. Of course, in Figure 6 TTX could have suppressed a persistent $\mathrm{Na}^{+}$current like that described in cat neocortical pyramidal cells (Stafstrom et al., 1985). KYN (Fig. 5) should not suppress such a current. Nonetheless, due to electrotonic constraints within fine dendritic processes, it is conceivable that the repetitive depolarizations are unable to activate persistent currents that are easily triggered by local synaptic contacts.

Another mechanism that could be responsible for the sustained depolarization in basilar dendrites would be a transmitter-gated voltage-dependent prolonged inward current. Prolonged NMDA receptor-mediated EPSPs have been reported in the developing visual system (see Carmignoto and Vicini, 1992; Hestrin, 1992). In this regard the effects of CNQX shown in Figure 3 should be considered. These results could suggest that AMPA and not NMDA receptors are responsible for generation of the sustained depolarization. However, at the concentrations employed $(50 \mu \mathrm{M})$ CNQX can suppress NMDA as well as AMPA responses. KYN is well known to block each class of excitatory amino acid receptor. Thus, it is possible that NMDA receptors contribute to some extent to the generation of the sustained depolarization. NMDA receptors are present on the proximal basilar dendrites of immature CA3 pyramidal cells. Indeed, our previous studies have shown that the voltage dependency of the NMDA receptor at this site is generated in a unique manner and can dramatically modulate the intensity of electrographic seizures in the developing area CA3 (Brady et al., 1991). Thus, the relative roles that NMDA and AMPA receptors play in generation of sustained depolarization will 
have to be the subject of further study. However, it is clear from the results presented in this article that synaptic events mediated by an excitatory amino acid neurotransmitter play a key role in the generation of the sustained depolarization and electrographic seizures.

One cannot rule out the possibility that the sustained depolarization is in some part a product of potassium $\left(\mathrm{K}^{+}\right)$that accumulates extracellularly during an electrographic seizure. Activity-dependent changes in extracellular $\mathrm{K}^{+}$are unusually large in the developing nervous system (Connors et al., 1982; Swann et al., 1986b; Hablitz and Heinemann, 1987). Ion-sensitive microelectrode recordings have revealed large $\mathrm{K}^{+}$transients from numerous dendritic locations in the developing area CA3 (Swann et al., 1986b). During electrographic seizures the largest changes in extracellular $\mathrm{K}^{+}$occur in the proximal portions of the basilar dendrites. It is well established that glutaminergic synaptic transmission results in the release of $\mathrm{K}^{+}$in the extracellular space (Pumain and Heinemann, 1985). Thus, changes in $\mathrm{K}^{+}$may be the product of a unique form of recurrent excitatory synaptic transmission occurring in proximal basilar dendrites. Alternatively, if the extracellular space was unusually small or tortuous in the proximal basilar dendrites or if $\mathrm{K}^{+}$ clearing mechanisms were poorly developed at this site, $\mathrm{K}^{+}$ transients may not bc produced by a unique synaptic mechanism but a highly localized deficiency in $\mathrm{K}^{+}$buffering mechanism. The precise contribution extracellular $\mathrm{K}^{+}$makes to the sustained depolarization is unknown at this time.

It would be an oversimplification of the results presented in this article to conclude that, since the sustained depolarization is produced exclusively in the basilar dendrites, the repetitive discharges of electrographic seizures are produced only in the apical dendrites. It is not likely that such a perfect segregation of these latter physiological processes exists. Indeed, results suggest that the basilar dendrites produce both the rapid and the slow components of an afterdischarge. For instance, in Figure $2 A-3$, blockade of apical dendritic synapses by KYN did not abolish the repetitive depolarizations of the afterdischarge. This would suggest that both components of an afterdischarge are generated in the basilar dendrites. Indeed, recordings in Figures 6 and 7 are also consistent with this notion. An initial application of TTX to the basilar dendrites abolished the sustained depolarization, but additional TTX decreased the amplitude of the rapid depolarizations. This leads us to think that both components are produced in the basilar dendrites and that a segregation takes place between proximal and more distal aspects of the basilar dendrites.

Recordings in Figure $2 A-3$ raise one additional question: if the PDS is produced by synapses on apical dendrites, why is it unaffected by KYN application at this site? Actually, the field potential recordings in trace $\mathrm{C}$ are fully consistent with the notion that this event is generated in part in the apical dendrites. KYN application reversed the polarity of this field potential. A similar polarity reversal was reported when TTX was applied to apical dendrites during PDS generation in mature hippocampus (see Fig. 8 in Swann et al., 1986a). This can be explained if one considers that when recurrent excitatory synapses on apical dendrites are blocked, synapses on basilar dendrites would still be active. Consequently, a passive current source or positivity would be produced in the apical dendritic layer by the active current sinks on basilar dendrites. However, it is surprising that the amplitude of the PDS is not decreased by this treatment (trace A, Fig. 2A-3). One explanation for this result is that the synaptic input on basilar dendrites is so massive that it is sufficient to produce a full-blown PDS.

Twenty-five years ago the role the sustained depolarization played in seizure generation was the subject of discussion. While some investigators supported its role in seizure generation, others did not. The most cogent arguments against its role were observations that some cells simply did not undergo a slow depolarization, yet underwent rapid repetitive depolarizations during electrographic seizures. Sawa et al. (1968) attempted to explain these observations by arguing that during seizures neurons could exist in one of several seizure states. For instance, at a site of seizure initiation (in their experimental model this was thought to be the site in cortex where repetitive electrical stimuli were applied) "generator" neurons were known to undergo a sustained depolarization concurrent with intense repctitive depolarizations. However, at a distance, neurons could exist in what was referred to as a "projected seizure state." In such a state a neuron was considered a passive contributor to seizure generation in that it was only driven by the repetitive discharges in generator cells. That is, its activity reflected only the massive synchronized input from neurons located at the site of seizure initiation. Cells in this state were thought to be ones that underwent the repetitive discharging of an ictal episode but did not tonically depolarize.

Given the relative simplicity of the in vitro experimental model employed in our study, it was possible to test directly the idea that the generation of a sustained depolarization was critical for production of seizures. This was because the hypothesized generator neurons and cells in the projected seizure state could be produced experimentally and monitored simultaneously. Results of our experiments are fully consistent not only with the notion that the sustained depolarization plays a critical role in seizures, but also that neurons can exist in a projected seizure state. In Figures 6 and 7, the discharging of neurons that were considered to be in the projected seizure state consistently followed those in the generator population. CNQX application to the apical dendrites blocked the discharges in these follower cells while discharges in the remote generator population were unaltered. Treatment of the generator network in Figure 5 in such a way that suppressed the sustained depolarization in these cells blocked electrographic seizure generation.

The results of our studies also suggest that 1- and 2-week-old rat hippocampal neurons project locally to both apical and basilar dendrites of many nearby pyramidal cells. Indeed, a detailed morphometric analysis of axons from single CA3 pyramidal cells has demonstrated an extensive local axon arborization within the proximal half of stratum oricns and radiatum (Swann et al., 1991). Thousands of varicosities are present on these axons. Every pyramidal cell examined thus far has similar extensive local projections. These results support the electrophysiologic findings in this study. They also reinforce the notion that normally during an electrographic seizure in immature hippocampus a single neuron can play the role of both a generator cell and a follower cell in seizure generation. This is a basic property of a neuron in a network of mutually excitatory cells.

\section{References}

Amaral DG (1978) A Golgi study of cell types in the hilar region of the hippocampus in the rat. J Comp Neurol 182:851-914.

Amaral DG, Witter MD (1989) The three-dimensional organization of the hippocampal formation: a review of anatomical data. Neuroscience 31:571-591.

Andersen P (1975) Organization of hippocampal neurons and their 
interconnections. In: The hippocampus, Vol 1, Structure and development (Isaacson RL, Pribraw KH, eds), pp 155-175. New York: Plenum.

Anderson WW, Lewis DV, Swartzwelder LHS, Wilson WA (1986) Magnesium-free medium activates seizure-like events in the rat hippocampal slice. Brain Res 398:215-219.

Brady RJ, Swann JW (1986) Ketamine selectively suppresses synchronized afterdischarges in immature hippocampus. Neurosci Lett 66:143-149.

Brady RJ, Swann JW (1988) Suppression of ictal-like activity by kynurenic acid does not correlate with its efficacy as an NMDA receptor antagonist. Epilepsy Res 2:232-238.

Brady RJ, Smith KL, Swann JW (1991) Calcium modulation of the $N$-methyl-D-aspartate response and electrographic seizures in immature hippocampus. Neurosci Lett 124:92-96.

Carmignoto G, Vicini S (1992) Activity-dependent decrease in NMDA receptor responses during development of the visual cortex. Science 258:1007-1011.

Connors BE, Ransom BR, Kunis DM, Gutnick MJ (1982) Activitydependent $\mathrm{K}^{+}$accumulation in the developing rat optic nerve. Science 216:1341-1343.

Creutzfeldt OD, Watanabe S, Lux HD (1966) Relations between EEG phenomena and potentials of single cortical cells. II. Spontaneous and convulsoid activity. Electroencephalogr Clin Neurophysiol 20:19-37.

Deitch JS, Smith KL, Lee CL, Swann JW, Turner JN (1990) Confocal scanning laser microscope images of hippocampal neurons intracellularly labeled with biocytin. J Neurosci Methods 33:61-76.

Deitch JS, Smith KL, Swann JW, Turner JN (1991) Ultrastructural investigation of neurons identified and localized using the confocal scanning laser microscope. J Electron Microsc Tech 18:82-90.

Dichter M, Spencer WA (1969) Penicillin-Induced interictal discharges from the cat hippocampus. II. Mechanisms undcrlying origin and restriction. J Neurophysiol 32:663-687.

Gilbert CD (1983) Microcircuitry of the visual cortex. Annu Rev Neurosci 6:217-247.

Gilbert CD, Wiesel TN (1983) Clustered intrinsic connections in cat visual cortex. J Neurosci 3:1116-1133.

Gloor P, Sperti L, Vera CL (1964) A consideration of feedback mechanisms in the genesis and maintenance of hippocampal seizure activity. Epilepsia 5:213-238.

Gutnick MJ, Connors BW, Prince DA (1982) Mechanisms of neocortical epileptogenesis in vitro. J Neurophysiol 48:1321-1335.

Hablitz JJ (1987) Spontaneous ictal-like discharges and sustained potential shifts in the developing rat neocortex. J Neurophysiol 58:10521065.

Hablitz JJ, Heinemann $U$ (1987) Extracellular $\mathrm{K}^{+}$and $\mathrm{Ca}^{2+}$ changes during epileptiform discharges in the immature rat neocortex. Dev Brain Res 36:299-303.

Hestrin S (1992) Developmental regulation of NMDA receptor-mediated synaptic currents at a central synapse. Nature 357:686-689.

Honore T, Davies SN, Drejer J, Fletcher EJ, Jacobsen P, Lodge D, Nielsen E (1988) Quinoxalinediones: potent competitive non-NMDA glutamate receptor antagonists. Science 241:701-703.

Ishizuka N, Weber I, Amaral DG (1990) Organization of intrahippocampal projections originating from CA3 pyramidal cells in the rat. J Comp Neurol 295:580-623.

Jaffe DB, Johnston D, Lasser-Ross N, Lisman JE, Miyakawa H, Ross WN (1992). The spread of $\mathrm{Na}^{+}$spikes determines the pattern of dendritic $\mathrm{Ca}^{2+}$ entry into hippocampal neurons. Nature 357:244-246.

Johnston D, Brown TH (1981) Giant synaptic potential hypothesis for epileptiform activity. Science 211:294-297.

Kandel ER, Spencer WA (1961a) Excitation and inhibition of single pyramidal cells during hippocampal seizure. Exp Neurol 4:162-179.

Kandel ER, Spencer WA (1961b) The pyramidal cell during hippocampal seizure. Epilepsia 2:63-69.

Katz B, Miledi R (1967) A study of synaptic transmission in the absence of nerve impulses. J Physiol (Lond) 192:407-436.
Knowles WD, Traub RD, Strowbridge BW (1987) The initiation and spread of epileptiform bursts in the in vitro hippocampal slice. Neuroscience $21: 441-455$.

Konnerth A, Heinemann U, Yaari Y (1986) Nonsynaptic epileptogenesis in the mammalian hippocampus in vitro. I. Development of seizure-like activity in low extracellular calcium. J Neurophysiol 56: $409-423$.

Llinas RR (1988) The intrinsic electrophysiological properties of mammalian neurons: insights into central nervous system function. Science 242:1654-1664.

Matsumoto H, Ajmone-Marsan C (1964) Cortical cellular phenomena in experimental epilepsy: ictal manifestation. Exp Neurol 9:305-326.

Miles R, Wong RKS, Traub RD (1984) Synchronized afterdischarges in the hippocampus: contribution of local synaptic interactions. Neuroscience 12:1179-1189.

Pumain R, Heinemann, U (1985) Stimulus- and amino acid-induced calcium and potassium changes in rat neocortex. $\mathrm{J}$ Neurophysiol 53: $1-16$.

Purpura DP, McMurtry JG, Leonard CF, Malliani A (1966) Evidence for dendritic origin of spikes without depolarizing prepotentials in hippocampal neurons during and after seizure. J Neurophysiol 29: 954-979.

Ross WN, Werman R (1987) Mapping calcium transients in the dendrites of Purkinje cells from the guinea-pig cerebellum in vitro. J Physiol (Lond) 389:319-336.

Sawa M, Maruyama N, Kaji S (1963) Intracellular potential during electrically induced seizures. Electroencephalogr Clin Neurophysiol 15:209-220.

Sawa M, Nakamura K, Naito H (1968) Intracellular phenomena and spread of epileptic seizure discharges. Electroencephalogr Clin Neurophysiol 24:146-154.

Smith KL, Swann JW (1987) Carbamazepine suppresses synchronized afterdischarging in disinhibited immature rat hippocampus in vitro. Brain Res 400:371-376.

Stafstrom CE, Schwindt PC, Chubb MC, Crill WE (1985) Properties of persistent sodium conductance and calcium conductance of layer $\mathrm{V}$ neurons from cat sensorimotor cortex in vitro. J Neurophysiol 37: $153-170$.

Swann JW, Brady RJ (1984) Penicillin-induced epileptogenesis in immature rat CA3 hippocampal pyramidal cells. Dev Brain Res 12: 243-254.

Swann JW, Brady RJ, Friedman RJ, Smith EJ (1986a) The dendritic origins of penicillin-induced epileptogenesis in CA3 hippocampal pyramidal cells. J Neurophysiol 56:1718-1738.

Swann JW, Smith KL, Brady RJ (1986b) Extracellular K+ accumulation during penicillin-induced epileptogenesis in the $\mathrm{CA} 3$ region of immature rat hippocampus. Dev Brain Res 30:243-255.

Swann JW, Gomez CM, Rice FL, Smith KL, Turner JN (1991) Anatomical studies of $\mathrm{CA}_{3}$ hippocampal neurons during postnatal development. Soc Neurosci Abstr 17:1131.

Tank DW, Sugimori M, Connor JA, Llinas RR (1988) Spatially resolved calcium dynamics of mammalian Purkinje cells in cerebellar slice. Science 242:773-777.

Taylor CP, Dudek FE (1984) Synchronization without active chemical synapses during hippocampal afterdischarges. J Neurophysiol 52:143155.

Traub RD, Wong RKS (1982) Cellular mechanism of neuronal synchronization in epilepsy. Science 216:745-747.

Traynelis SF, Dingledine R (1988) Potassium-induced spontaneous electrographic seizures in the rat hippocampal slice. J Neurophysiol 59:259-276.

Valverde F (1986) Intrinsic neocortical organization: some comparative aspects. Neuroscience 18:1-23.

Wong RKS, Traub RD (1983) Synchronized burst discharge in disinhibited hippocampal slice. I. Initiation in CA2-CA3 region. J Neurophysiol 49:442-457. 